\title{
UNA APROXIMAGIÓN PRAGMÁTICA A LA CAPAGIDAD CONTRIBUTIVA DE UN ASALARIADO DE CLASE MEDIA. ESTUDIO COMPARADO ENTRE MÉXICO Y ESPAÑA*
}

\author{
Kenny IRIGOYEN BASTERIS**
}

SUMARIO: I. Introducción. II. Análisis de la capacidad contributiva de los trabajadores de clase media en México. III. Derecho al mínimo vital en la legislación mexicana. IV. Derecho comparado: caso España. V. Conclusiones y recomendaciones finales. VI. Bibliografia.

\section{INTRODUCGIÓN}

Una regularidad empírica en el proceso de desarrollo económico es la expansión de la clase media: a medida que el nivel de ingresos por persona aumenta y los países se desarrollan y se modernizan, la importancia relativa de la clase media aumenta. ${ }^{1}$

La clase media y trabajadora es una fuerza vital en una nación, mientras más habitantes de clase media existan, más equilibrado y justo es el nivel de vida de los habitantes en ese país.

Este estudio pretende elaborar un análisis de la contribución de un trabajador de clase media en el régimen del impuesto sobre la renta de ingresos por salarios. Partiendo del hecho que en México el régimen de salarios tiene un esquema muy limitado de deducciones y el trabajador paga impuestos prácticamente sobre casi todo su ingreso bruto. Lo anterior, con la excepción de aquellos trabajadores que tienen un salario bajo, a los cuales

\footnotetext{
* Artículo recibido el 8 de enero de 2018 y aceptado para su publicación el 26 de enero de 2018.

** ORCID: 0000-0001-7459-3951

1 Bárcena, A. y Serra, N. en su estudio sobre las clases medias en 130 países sugieren que a medida que los niveles de ingreso per cápita crecen y el nivel de desarrollo aumenta, los países tienden a tener una clase media más amplia con poder de consumo creciente y un mercado interno más extenso.
}

Boletín Mexicano de Derecho Comparado, nueva serie, año XLX, núm. 152, mayo-agosto de 2018, pp. 837-868. 
el Estado mexicano los subsidia mediante el decreto del subsidio para el empleo. ${ }^{2}$

En México, la contribución de las personas físicas con ingresos por salarios constituye un ingreso medular para el Estado Mexicano, como se puede observar en los siguientes datos:

\section{IMPUESTO SOBRE LA RENTA, 2014-2015 \\ MILLONES DE PESOS}

\begin{tabular}{|l|c|c|c|c|}
\hline \multicolumn{1}{|c|}{ Concepto } & 2014 & $\%$ & 2015 & $\%$ \\
\hline Personas morales & 441,317 & $45 \%$ & 592,443 & $48 \%$ \\
\hline Personas físicas retenciones por salarios & 473,233 & $48 \%$ & 580,548 & $47 \%$ \\
\hline Otros ingresos de personas físicas & 40,976 & $4 \%$ & 28,836 & $2 \%$ \\
\hline Retenciones a residentes en el extranjero & 31,076 & $3 \%$ & 36,269 & $3 \%$ \\
\hline Total & 986,602 & $100 \%$ & $1,238,096$ & $100 \%$ \\
\hline
\end{tabular}

FUENTE: Servicio de Administración Tributaria, "Reporte anual 2015 y retos 2016".

En el recuadro anterior puede identificarse que el rubro de retenciones por salarios de las personas físicas aporta de forma muy significativa a la recaudación de impuesto sobre la renta (ISR) en nuestro país. En el 2014 representó el 48\% de la recaudación del ISR e incluso los asalariados pagaron más impuesto que las personas morales. En el ejercicio 2015 representó el 47\% del ISR. Estas cifras nos dan una idea de la importancia que tiene la contribución de los asalariados en nuestro país.

El Estado debe sostenerse de las contribuciones provenientes de sus habitantes, pero la cuestión a discutir siempre ha sido ¿en qué medida debe contribuir cada uno? la respuesta puede parecer obvia, de manera justa. ${ }^{3}$

Pero, ¿Cómo se logra la contribución justa? Ernesto Flores Zavala, considera que para alcanzar la justicia se necesitan establecer dos principios básicos: la generalidad y la uniformidad. ${ }^{4}$

2 El subsidio para el empleo que actualmente se encuentra en el decreto del 11 de diciembre de 2013 obliga a los patrones a entregar una cantidad en efectivo a aquellos trabajadores que ganen hasta 7,382.33 pesos, el importe entregado por los patrones lo pueden acreditar contra su ISR corporativo o contra otras retenciones de ISR por enterar.

3 Venegas Álvarez, S., Derecho fiscal parte general e impuestos federales, México, Oxford, 2016, p. 64 .

4 Flores Zavala, E., La justicia en los impuestos, México, Librería Madero, 1955, p.7.

Esta obra está bajo una Licencia Creative Commons

Atribución-NoComercial-SinDerivar 4.0 Internacional, IIJ-UNAM.

Boletín Mexicano de Derecho Comparado, núm. 152, pp. 837-868. 
La generalidad implica que todo aquel que posea capacidad contributiva aporte al erario, mientras que la uniformidad exige igual sacrifico económico entre aquellos que estén en igualdad de circunstancias.

El acreedor tributario sólo podrá exigir al sujeto pasivo una aportación apegada a su aptitud contributiva. Tales argumentos representan la esencia del Estado de derecho, pero, a su vez, de la estabilidad social de un país. ${ }^{5}$

Este estudio no pretende ser un análisis de la legalidad de la contribución de las personas físicas por salarios, pero aborda de una forma práctica la imposición que está teniendo un trabajador mexicano de clase media y analiza si con la actual legislación se le está cobrando una contribución justa que le permita al trabajador tener una vida digna y que respete el principio de capacidad contributiva o capacidad económica. ${ }^{6}$

La base de la investigación es de tipo documental y se complementó con cálculos propios para determinar de forma inductiva y práctica si la contribución tributaria es justa y acorde con la realidad económica observada en los trabajadores de clase media. Asimismo, se utiliza el derecho comparado para contrastar el estado de la situación en México y España.

\section{ANÁLISIS DE LA GAPACIDAD CONTRIBUTIVA \\ DE LOS TRABAJADORES DE CLASE MEDIA EN MÉXICO}

\section{1. ¿Quién es un habitante de clase media en México?}

Según el Instituto Nacional de Estadística y Geografía (Inegi) el 39.2\% de la población es de clase media en México. De acuerdo a este organismo, si de la clase media se selecciona un hogar al azar en México, lo más probable es que este hogar:

5 García Bueno, M., "El principio de capacidad contributiva como criterio esencial para una reforma fiscal", en Ríos Granados, Gabriela (coord.), Conceptos de reforma fiscal, México, UNAM, 2002, p. 47.

6 Coincidimos con Pont Mestres cuando establece que el principio de capacidad económica establecido en la Constitución Española tiene el mismo significado que el principio de capacidad contributiva establecido en la Constitución italiana y en la doctrina mexicana. Al respecto, señala: “...pienso que ambas locuciones en tanto que conectadas con la distribución de los tributos tienen idéntica significación y contenido”.

Esta obra está bajo una Licencia Creative Commons Atribución-NoComercial-SinDerivar 4.0 Internacional, IIJ-UNAM. Boletín Mexicano de Derecho Comparado, núm. 152, pp. 837-868. 
- Cuente con una computadora.

- Gaste 4,380 pesos trimestrales en alimentos y bebidas fuera del hogar.

- Abone alrededor de 1,660 pesos a tarjetas de crédito trimestralmente.

- Guente con al menos un integrante asalariado con contrato escrito y labore para una empresa con razón social del sector privado.

- La cabeza del hogar tiene, al menos, educación media superior y está casado.

- La familia cuente con cuatro integrantes.

- Los hijos asistan a escuelas públicas.

- La vivienda es propia o se está pagando, financiada con recursos de la familia o crédito de interés social. ${ }^{7}$

Por otro lado, el mismo instituto en su Encuesta Nacional de Ingresos y Gastos en los Hogares efectuada (ENIGH) en el 2014, determina que el ingreso monetario promedio mensual de un hogar es de 10,534 pesos y el gasto monetario corriente es de 8,823 pesos el cual se integra principalmente de los siguientes rubros:

TABLA 1

GASTO CORRIENTE MONETARIO POR HOGAR EN PESOS MEXICANOS

\begin{tabular}{|l|c|}
\hline \multicolumn{1}{|c|}{ Gasto corriente monetario promedio por hogar } & Importe mensual 2014 \\
\hline Alimentos, bebidas y tabaco & 3,010 \\
\hline Vestido y calzado & 413 \\
\hline Vivienda y combustibles & 836 \\
\hline Artículos y servicios para la casa & 546 \\
\hline Cuidados de la salud & 218 \\
\hline Transporte y comunicaciones & 1,657 \\
\hline Educación y esparcimiento & 1,238 \\
\hline
\end{tabular}

7 Inegi, "Cuantificando la clase media en México: un ejercicio exploratorio", disponible en: http://wrww.inegi.org.mx/inegi/contenidos/investigacion/experimentales/clase_media/ presentacion.aspx.

Esta obra está bajo una Licencia Creative Commons

Atribución-NoComercial-SinDerivar 4.0 Internacional, IIJ-UNAM.

Boletín Mexicano de Derecho Comparado, núm. 152, pp. 837-868. 


\begin{tabular}{|l|c|}
\hline \multicolumn{1}{|c|}{ Gasto corriente monetario promedio por hogar } & Importe mensual 2014 \\
\hline Cuidados personales & 635 \\
\hline Transferencia de gasto & Total \\
\hline
\end{tabular}

FUENTE: ENIGH 2014.

Por lo tanto, para efectos de este estudio consideraremos, con base en la ENIGH de 2014, que un individuo de clase media es aquel con un ingreso mensual promedio de 10,534 pesos mensuales y un gasto de 8,823 pesos mensuales. ${ }^{8}$

\section{El Impuesto sobre la Renta de personas fisicas y las deducciones} personales en México

En México las personas físicas están obligadas al pago del ISR, por la obtención de distintos ingresos como son salarios, actividades empresariales y servicios profesionales, arrendamiento de inmuebles, intereses, premios, entre otros.

A estos ingresos por los cuales se paga el ISR de conformidad con la tarifa del artículo 152 de la Ley del Impuesto sobre la Renta (LISR) se les conoce como ingresos gravados. Cabe señalar que existen ciertos ingresos exentos en la propia ley sobre los cuales no se paga el impuesto.

Por otro lado, la LISR permite disminuir del ingreso gravado ciertos gastos a los cuales se les conoce como deducciones autorizadas. Estas deducciones son distintas dependiendo del tipo de ingreso que se obtenga, es decir, a cada tipo de ingreso se le permite disminuir cierto tipo de deducciones, o, en su caso, no se le permiten.

8 Es de llamar la atención que el Inegi considere de clase media a una persona que tiene un ingreso de hasta 10,500 pesos al mes, personalmente consideramos que no es un ingreso suficiente para tener una calidad de vida "media" en México. Sin embargo, tomaremos como válido este dato en nuestro estudio por ser el organismo oficial en nuestro país. La OCDE, en cambio, por ejemplo ha determinado que el ingreso promedio mensual por salarios en México es de 1,239 dólares americanos, es decir aproximadamente 23,000 pesos al mes (a un tipo de cambio de 18.6909 publicado en el Diario Oficial de la Federación el 2 de junio de 2017), consideramos que un salario con el monto de la media de la OCDE podría ser un nivel más adecuado para considerarlo de clase media en México. 
En adición a las deducciones autorizadas, existen las que se conocen como deducciones personales, las cuales son atribuibles a todas las personas físicas independientemente del tipo de ingreso que obtengan y estas se pueden disminuir cuando la persona física presenta una declaración anual. Ambas deducciones deben obedecer al principio de capacidad contributiva.

En este estudio se hace hincapié que para el caso de los ingresos por salarios no se pueden efectuar deducciones autorizadas específicas para el régimen, a diferencia de otros ingresos gravados de las personas físicas en las que sí es posible. Sin embargo, la tarifa establecida en el artículo 152 de la LISR para el cálculo anual del impuesto de las personas físicas, en general, es la misma independientemente del tipo de ingreso obtenido.

Así las cosas, los asalariados únicamente tienen la posibilidad de aplicar las deducciones personales, que de conformidad con el artículo 151 de la LISR son las siguientes:

a) los pagos por honorarios médicos, dentales y por servicios profesionales en materia de psicología y nutrición;

b) los gastos de funerales;

c) los donativos no onerosos ni remunerativos;

d) los intereses reales efectivamente pagados en el ejercicio por créditos hipotecarios destinados a la adquisición de su casa habitación;

e) las aportaciones complementarias a las cuentas de retiro;

f) las primas por seguros de gastos médicos, y

g) los gastos destinados a la transportación escolar de los descendientes en línea recta cuando ésta sea obligatoria.

Además, son deducibles los pagos por colegiaturas desde preescolar hasta bachillerato con ciertos límites en virtud de un estímulo fiscal. ${ }^{9}$

El monto total de las deducciones personales, excepto donativos, aportaciones complementarias al retiro y colegiaturas, no pueden exceder de cinco Unidades de Medida y Actualización (UMA) anuales (que en el 2017 este importe asciende a 137,769 pesos) o del 15\% del total de los ingresos de la persona, lo que resulte menor.

9 Decreto que compila diversos beneficios fiscales y establece medidas de simplificación administrativa, publicado en el Diario Oficial de la Federación del 30 de marzo de 2012, vigente a la fecha.

Esta obra está bajo una Licencia Creative Commons

Atribución-NoComercial-SinDerivar 4.0 Internacional, IIJ-UNAM.

Boletín Mexicano de Derecho Comparado, núm. 152, pp. 837-868. 
Los donativos no pueden exceder del 7\% de los ingresos y las aportaciones para el retiro no podrán exceder del 10\% de los ingresos o de cinco UMA elevado al año (que en el 2017 asciende a 137,769 pesos).

El límite para la deducción del estímulo fiscal a las colegiaturas es el siguiente:

\begin{tabular}{|l|c|}
\hline \multicolumn{1}{|c|}{ Nivel educativo } & Limite anual de deducción (pesos) \\
\hline Preescolar & 14,200 \\
\hline Primaria & 12,900 \\
\hline Secundaria & 19,900 \\
\hline Profesional técnico & 17,100 \\
\hline Bachillerato o equivalente & 24,500 \\
\hline
\end{tabular}

FUENTE: Decreto que compila diversos beneficios fiscales y establece medidas de simplificación administrativa, publicado en el Diario Oficial de la Federación del 30 de marzo de 2012.

Como se puede observar, el catálogo de deducciones personales es mínimo y en adición a esto tiene limitantes en monto y en porcentaje. Algunos de los gastos más relevantes que incurren las personas y que no se consideran como deducción personal de acuerdo a los conceptos del ENIGH en la tabla 1 son los siguientes: alimentos y bebidas, vestido y calzado, gastos en la vivienda, gastos por combustibles, transporte y comunicaciones, cuidados personales.

\section{Cálculo del porcentaje de retención efectiva de un trabajador de clase media en México}

Para efectos de determinar un análisis numérico de la carga fiscal que tiene un asalariado de clase media realizaremos el cálculo de su impuesto anual y determinaremos una tasa efectiva de impuestos que posteriormente se detallará.

La tasa efectiva es un indicador que utilizaremos en este estudio para determinar el porcentaje real que representa el impuesto pagado por el trabajador, en dos situaciones: 
- Sobre los ingresos gravables según lo estipulado por la legislación,

- Sobre sus ingresos netos, que serían sus ingresos gravables después de disminuir sus erogaciones reales y no sólo las permitidas por la Ley. ${ }^{10}$

Realizaremos el cálculo del ISR que obtendría un trabajador de clase media en su declaración anual, en el supuesto que tenga un ingreso mensual de 10,534 y un gasto mensual de 8,223 pesos de conformidad con los promedios señalados por el Inegi, mencionados anteriormente en este estudio. Así las cosas, el ingreso anual equivaldría al monto de 126,408 pesos y su gasto anual a 105,876 pesos.

De los gastos señalados en la tabla 1 de este estudio se puede verificar que la mayoría de conceptos no se pueden deducir de los ingresos por salarios como deducciones personales. Sin embargo, para nuestro cálculo se asume que el asalariado pueda reunir el tope máximo de los conceptos de gastos más comunes considerados como deducciones personales establecidos en la LISR. Entonces, tomaremos el 15\% su ingreso gravable para determinar las deducciones personales.

Con todos los supuestos anteriores, su impuesto calculado de conformidad con la tarifa establecida en el artículo 152 de la LISR de 2017 quedaría como sigue:

10 La noción de renta bruta o renta neta (ingreso menos deducciones) no es novedosa, los tribunales alemanes la han estudiado ampliamente. Para mayor información de este tema, recomendamos confrontar a Herrera Molina, Pedro, Capacidad económica y sistema fiscal, análisis del ordenamiento español a la luz del derecho alemán, Madrid, Marcial Pons, 1998.

Esta obra está bajo una Licencia Creative Commons

Atribución-NoComercial-SinDerivar 4.0 Internacional, IIJ-UNAM.

Boletín Mexicano de Derecho Comparado, núm. 152, pp. 837-868. 


\author{
CÁlculo 1 \\ DETERMINAGIÓN DEL ISR ANUAL Y TASA EFECTIVA \\ SOBRE LA BASE GRAVABLE DE UN ASALARIADO DE CLASE MEDIA \\ (PESOS MEXICANOS)
}

Ingreso anual

(-) Deducciones personales (15\%)

(=) Base gravable

(-) Límite inferior de tarifa

(=) Excedente

(x) Porcentaje sobre el excedente

(=) Impuesto sobre el excedente

(+) Cuota fija

(=) Total de ISR

Tasa efectiva sobre ingresos netos $(\mathrm{a} / \mathrm{b})$

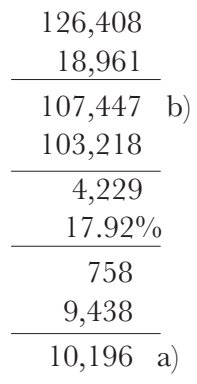

$9.49 \%$

FUENTE: Elaboración propia.

Para efectos de determinar una tasa efectiva de su impuesto debemos dividir el total de ISR que esta persona pagaría entre la Base gravable. Este indicador nos da una idea más precisa y realista de la carga fiscal de una persona física.

En el supuesto anterior el trabajador estaría pagando una tasa efectiva del $9.49 \%$, lo cual pudiera parecer que no es una carga fiscal excesiva. Sin embargo, la base gravable para efecto de la determinación no es el remanente de dinero real del trabajador después de obtener sus ingresos y pagar sus gastos en el hogar.

Si calculamos nuevamente la tasa efectiva, pero en lugar de restar las deducciones personales de la LISR utilizamos los gastos promedios anualizados que realmente tendría que pagar un asalariado de clase media con base en el ENIGH se obtendría lo siguiente: 


\section{CÁlculo 2 \\ DETERMINAGIÓN DE LA TASA EFEGTIVA DE UN ASALARIADO DE CLASE MEDIA CONSIDERANDO SUS GASTOS REALES (PESOS MEXICANOS)}

Ingreso anual

(-) Deducciones personales $(15 \%)$

(=) Ingresos netos

(-) ISR pagado

(=) Saldo para el ahorro o inversión

Tasa efectiva sobre ingresos netos $(\mathrm{a} / \mathrm{b})$

$$
\begin{array}{rr}
\begin{array}{r}
126,408 \\
105,876
\end{array} \\
\cline { 1 - 1 } 20,532 & \text { b) } \\
10,196 & \text { a) } \\
\hline 10,336 &
\end{array}
$$

FUENTE: Elaboración propia.

Como se puede observar, la persona física de clase media tiene disponible la cantidad de 20,532 pesos en un año después de cubrir con sus ingresos por salarios los gastos que podría tener en su hogar. A esta cantidad le hemos denominado "ingresos netos" en este estudio.

Se puede observar como en el segundo cálculo el ISR determinado que pagaría la persona representa prácticamente el 50\% de sus ingresos netos, es decir de lo que percibe por su trabajo menos los gastos reales que tendría que desembolsar.

Esto significa, que a un trabajador de clase media le está quedando una cantidad mínima disponible para ahorrar o invertir en su patrimonio ya que el impuesto que pagó en un año representa la mitad del dinero que le quedaba luego de cubrir sus gastos necesarios para vivir.

\section{DEREGHO AL MÍNIMO VITAL EN LA LEGISLAGIÓN MEXICANA}

Un principio plenamente relacionado con el de la capacidad contributiva, objeto de nuestro estudio, es el del derecho al mínimo vital o derecho al mínimo existencial, como también se le conoce.

El derecho al mínimo vital obliga al legislador a analizar si la persona que no dispone de los recursos materiales necesarios para subsistir de ma- 
nera digna, debe ser o no sujeta de ciertas cargas fiscales que le ocasionen una situación de penuria. ${ }^{11}$

Este concepto señala qué elementos debe considerar el legislador para imponer contribuciones, contemplando de igual manera los principios constitucionales de proporcionalidad y equidad. Un aspecto importante en el que también se fundamenta este principio es la dignidad de la persona, protegida por la Constitución Política de los Estados Unidos Mexicanos.

En los amparos en revisión 1780/2006 y 811/2008 resueltos por la Primera Sala de la SCJN se emitió pronunciamiento sobre la existencia del derecho al mínimo vital como un límite para el legislador tributario en la imposición de tributos, mientras que la Segunda Sala, específicamente en el amparo en revisión 1301/2006, determinó que el legislador ordinario no puede imponer contribuciones a quienes perciben el salario mínimo, como retribución apenas suficiente para cubrir las necesidades de esas personas.

Vale la pena mencionar que el pleno de la SCJN en septiembre de 2011 se pronunció finalmente al respecto y determinó que la justicia de la unión no ampara ni protege a diversos particulares que promovieron el amparo contra los artículos 177 y 178 de la LISR, en los cuales se establecía la Tarifa para el impuesto y el Subsidio para el pago del ISR del ejercicio de las personas físicas basando su demanda en el principio del mínimo vital. (Amparos en revisión 2237/2009, 24/2010, 121/2010, 204/2010, $507 / 2010)$.

$\mathrm{Al}$ respecto la Suprema Corte de Justicia de la Nación hizo las siguientes consideraciones: ${ }^{12}$

1. El derecho al mínimo vital no debe ser contemplado únicamente como un mínimo para la supervivencia económica (artículo 31, fracción IV, constitucional), sino también para la existencia libre y digna a la que se refiere el artículo 25 de la Constitución Federal (efectiva participación de todos los ciudadanos en la organización política, económica, cultural y social del país). También debe agregarse el contenido de la fracción VIII del apartado A del

11 Cfr. EY Tax Flash, "Derecho al Mínimo Vital", publicación electrónica de Ernst \& Young, 2007, p. 1, disponible en: http://wrere.eyboletin.com.mx/eysite2/index.php?'option=com_co ntentEtask=view Eid $=378$ \& Itemid $=9$.

12 Véase http://wrww2.scjn.gob.mx/AsuntosRelevantes/pagina/SeguimientoAsuntosRelevantesPub.aspx:ID=114032 ESeguimientoID=274, consultado el 23 de abril de 2017 . 
artículo 123 de dicha Constitución, en el sentido de que el salario mínimo quedará exceptuado de embargo, compensación o descuento.

Ello, es concordante con lo establecido en instrumentos internacionales, en los que se refleja la proyección que debe tener el Estado para garantizar que el ciudadano pueda allegarse de los elementos necesarios para tener una calidad de vida digna y decorosa, tales como la Declaración Americana de los Derechos y Deberes del Hombre y las Directrices de Maastricht sobre Violaciones a los Derechos Económicos, Sociales y Culturales.

2. Los quejosos argumentan que la tarifa del artículo 177 del ISR reclamado es inconstitucional por someter a gravamen a los ingresos de las personas desde el primer centavo que perciban de ingresos, sin que para ello exista una excepción a la carga tributaria por un mínimo de percepciones que sirvan para vestido, vivienda, alimentación, gastos médicos, de recreación, tanto para dichas personas físicas contribuyentes, como para su familia.

Los proyectos declararon infundado el argumento. Si bien es cierto que el principio de proporcionalidad tributaria demanda que las manifestaciones de capacidad económica que no resulten idóneas para contribuir, no se vean afectadas por el sistema fiscal, no lo es menos que existen diversas circunstancias que permiten concluir que la consecución de tales objetivos no debe quedar sujetada a los efectos de una particular figura jurídica.

3. El sistema general de tributación del Título IV de la LISR, no deja de respetar el derecho al mínimo vital, en su vertiente vinculada a la garantía de proporcionalidad tributaria, lo cual es efectuado a través de diversos mecanismos.

Dichos mecanismos son aquéllos propios de la legislación fiscal atendiendo al tipo de ingreso que se percibe (personas físicas que obtienen ingresos por salarios, personas físicas que obtienen ingresos por actividades empresariales, así como por la prestación de servicios personales subordinados), o bien, independientemente del tipo de ingreso que se percibe (deducciones personales).

Es importante mencionar que este análisis efectuado por el Pleno de la SCJN lo realizó sobre la LISR publicada en el Diario Oficial de la Federación $(D O F)$ el 1o. de enero de 2002, la cual actualmente se encuentra abrogada. En la legislación actual las personas físicas vieron aún más afectada su capacidad contributiva porque las deducciones personales fueron limitadas al 15\% de los ingresos del contribuyente. Esto particularmente afecta a los asalariados los cuales son personas que subsisten normalmente sólo con este ingreso y no tienen derecho a ninguna deducción más que a las deducciones personales, por lo que consideramos que sería relevante que la corte

Esta obra está bajo una Licencia Creative Commons

Atribución-NoComercial-SinDerivar 4.0 Internacional, IIJ-UNAM.

Boletín Mexicano de Derecho Comparado, núm. 152, pp. 837-868. 
tomara este caso nuevamente pero en función de la limitante establecida por la LISR vigente la publicada en el DOF el 11 de diciembre de 2013.

Resulta evidente el sentido en el cual el Pleno de la SCJN iba a fallar, ya que si bien lo que se disputaba era que si las cargas tributarias a las persona físicas resultaban excesivas afectando así el derecho a una vida digna y decorosa, no es menos cierto que las disposiciones fiscales establecen beneficios fiscales para las personas que perciban únicamente el salario mínimo, entiendo así que la supervivencia alimentaria de los trabajadores no se ve afectada por las cargas contributivas. Anulando de este modo la posibilidad para acceder a este derecho mínimo vital a la clase media, para la cual se convirtió en "papel mojado".

Ahora bien, si analizamos el caso sujeto a estudio, es un hecho que las autoridades mexicanas consideren erróneamente, que basta con que se satisfaga la necesidad de alimentos para cumplir con el requisito de tener una vida digna y decorosa. En este sentido planteamos la interrogante ¿el tener ingresos netos que únicamente cubran la necesidad de alimento es tener una vida digna y decorosa, dirigida únicamente a la población denominada "pobre"?, o ¿la vida digna y decorosa también se puede extrapolar a la clase media, otorgando más deducciones a las erogaciones necesarias como gastos médicos, alimentos, colegiaturas escolares, vivienda, etcétera?

Para responder a estas preguntas hay que entender desde una perspectiva más amplia el principio de la capacidad contributiva, el cual no debe analizarse constreñido únicamente a la obligación sustantiva del pago de las contribuciones, es decir, que debe considerarse que rige para todas aquellas relaciones de índole adjetiva o sustantiva que sean consecuencia de la potestad tributaria, ya que la capacidad contributiva no sólo se manifiesta de manera positiva obligando al particular a contribuir en la medida de su aptitud real, sino de manera negativa, prohibiendo a la autoridad recaudar cantidades superiores a las debidas, obligándola a retribuir al particular las sumas obtenidas injustificadamente, obligando al Estado a reparar la desigualdad que nace cuando una persona entrega una cantidad superior a la debida, reintegrándoles el quebrante patrimonial. ${ }^{13}$

Si la carga del estudio de la desigualdad, proporcionalidad y equidad de las contribuciones compete al Poder Legislativo, es un hecho que

13 González García, E., Concepto y contenido del derecho tributario, México, Porrúa, 2005. 
"no es cierto que el Poder Judicial de la Federación carezca de facultades para estudiar el problema de la proporcionalidad y equidad en los impuesto." "En este sentido, resultaría penoso considerar que la razón por la cual no hay mayores beneficios fiscales para gastos básicos de la clase media mexicana sea político o disminución en la recaudación de ingresos.

Así, ¿desde qué perspectiva convendría ver el derecho mínimo vital?, la legislación mexicana debería de descuadrar la visión tercermundista de dicho concepto, y comenzar a considerar gastos necesarios que la clase media realice con el fin de deducirlos, ya que para la capacidad contributiva real de la clase media consideramos debería de entenderse restando un porcentaje de alimentos, la totalidad de colegiaturas efectuadas y gastos de vivienda, entendiéndose estos no solamente los créditos hipotecarios sino también la rentas erogadas por arrendamientos.

Ante tales consideraciones, es difícil de creer que el concepto de la capacidad contributiva se respeta plenamente en México cuando tampoco existe en la legislación un mecanismo para contribuir de acuerdo a la situación personal y familiar del ciudadano. Es decir, la tarifa aunque denominada progresiva se aplica de igualmente a una persona soltera, que a una familia con hijos que cubre gastos de manutención, a una persona con discapacidad o de la tercera edad por mencionar diversas situaciones personales y familiares. Consideramos que debería ampliarse el sentido del mínimo vital en la legislación de México para cubrir estos aspectos.

En dicho contexto, podemos concluir que la clase media mexicana debería de obtener ingresos, después del pago de impuestos, suficientes "para satisfacer las necesidades de un jefe de familia en el orden material, social y cultural, y para proveer a la educación obligatoria de los hijos", es decir, más allá de solventar necesidades básicas para subsistir, la autoridades mexicanas deben entender como "«vida digna y decorosa», la que otorgue a sus ciudadanos la opción de ser autosuficientes, incrementar su patrimonio, y tener un nivel de vida más alto y con mayores beneficios económicos". ${ }^{15}$

14 Impuestos, equidad y proporcionalidad de los amparos en revisión 3280/50, Antonio Fernández y coagraviados, tesis aislada en materia administrativa, 16 de marzo de 1965, Semanario Judicial de la Federación, Sexta Época, t. XCIII, p. 36.

15 Consejo de Derechos Humanos, Proyecto final de los principios rectores sobre la extrema pobreza y los derechos humanos, presentado por la Relatora Especial sobre la extrema pobreza

Esta obra está bajo una Licencia Creative Commons

Atribución-NoComercial-SinDerivar 4.0 Internacional, IIJ-UNAM.

Boletín Mexicano de Derecho Comparado, núm. 152, pp. 837-868. 


\section{DERECHO COMPARADO: GASO ESPAÑA}

\section{Clase media en España}

De acuerdo con la Oficina Europea de Estadística, más conocida como "Eurostat", el ingreso promedio de un trabajador de España es de 2,287 euros mensuales, esto es aproximadamente 47,490 pesos mexicanos mensuales. Por su parte el Instituto Nacional de Estadística (INE) de España establece un ingreso promedio de 2,227 euros mensuales, esto es aproximadamente 46,250 pesos mexicanos mensuales por lo que ambos institutos determinaron importes similares.

Por otro lado, de acuerdo con el INE, el gasto promedio por hogar es de 1,787 euros mensuales, esto es aproximadamente 37,094 pesos mexicanos mensuales, y se conforma normalmente de las siguientes partidas:

\begin{tabular}{|l|c|c|}
\hline \multicolumn{1}{|c|}{ Gasto corriente monetario promedio por hogar } & $\begin{array}{c}\text { Importe mensual } \\
\text { 2015 (euros) }\end{array}$ & $\begin{array}{c}\text { Importe mensual } \\
2015 \text { (pesos) }\end{array}$ \\
\hline Alimentos y bebidas no alcohólicas & 337 & 6,989 \\
\hline Bebidas alcohólicas, tabaco y narcóticos & 43 & 900 \\
\hline Artículos de vestir y calzado & 116 & 2,413 \\
\hline Gastos en la vivienda, agua, electricidad, gas y otros & 247 & 5,123 \\
\hline $\begin{array}{l}\text { Mobiliario, equipamiento del hogar y gastos de con- } \\
\text { servación de la vivienda }\end{array}$ & 97 & 2,014 \\
\hline Salud & 81 & 1,681 \\
\hline Transporte & 263 & 5,460 \\
\hline Comunicaciones & 66 & 1,364 \\
\hline Ocio, espectáculos y cultura & 133 & 2,755 \\
\hline Enseñanza & 31 & 651 \\
\hline Hoteles, cafés y restaurantes & 202 & 4,198 \\
\hline Otros bienes y servicios & 171 & 3,546 \\
\hline & 1,787 & 37,094 \\
\hline
\end{tabular}

FUENTE: INE ${ }^{16}$

y los derechos humanos, Magdalena Sepúlveda Carmona, A/HRC/21/39 del 18 de julio de 2012, pfo. 84, inc. b, disponible en: http://wrwe.ohchr.org/Documents/Issues/Poverty/AHRC-21-39_sp.pdf (fecha de consulta: 26 de abril de 2017).

16 Tipo de cambio utilizado: 20.730, de acuerdo a la equivalencia del euro al último día de abril 2017, publicado en el Diario Oficial de la Federación el 8 de mayo de 2017. 
Es relevante mencionar que en España, de conformidad con el INE y el Eurostat aproximadamente el $46 \%$ de la población es de clase media.

\section{Breve reseña del principio de capacidad económica en España}

El derecho tributario español se fundamenta en diferentes principios que se reúnen principalmente en el artículo 31, apartados 1, 2 y 3 de la Constitución Española (CE), se señala en su apartado 1: "Todos contribuirán al sostenimiento de los gastos públicos de acuerdo con su capacidad económica mediante un sistema tributario justo inspirado en los principios de igualdad y progresividad que, en ningún caso tendrán alcance confiscatorio...".

Como se puede observar en el artículo 31 apartado 1 de la CE, el principio de la capacidad económica no se establece en como criterio único de justicia, sino que se encuentra vinculado con otros principios como el de igualdad, progresividad y no confiscatoriedad.

No obstante, el principio de capacidad económica de todos los principios enumerados, quizá pueda decirse que es el más trascendental no sólo en el momento de creación de la norma tributaria, sino también en el de su interpretación. De otra parte, su eficacia metodológica se proyecta en la dogmática de las instituciones tributarias. Es pues, el principio tributario por antonomasia. ${ }^{17}$

El principio de capacidad económica en España es un fundamento para la imposición un límite para el legislador tributario. Deberá establecer sus gravámenes dentro de unos límites máximos y mínimos de forma que no llegue a agotar la capacidad económica del contribuyente, la cual es la medida de su contribución a los gastos públicos. ${ }^{18}$

A pesar de lo anterior, podemos hablar que existe cierta flexibilidad en el principio de capacidad económica en España. Según lo han reconocido los tribunales españoles el principio de capacidad económica no es rígido, toda vez que el principio se respetará si la capacidad es real o potencial aunque el legislador persiga con el tributo atender a otro tipo de

17 Rosembuj, Tulio, Elementos de derecho tributario, Barcelona, PPU, 1998.

18 Fernández Amor, José Antonio y Masbernat, Patricio, "La vigencia de los principios de justicia tributaria en España: aportaciones para un debate", Estudios Constitucionales, Chile, vol. 11, núm. 2, 2013, p. 9. 
fines de interés público que prevea la $\mathrm{CE}$ diferentes la distribución equitativa de las cargas públicas. Abre con ello una posibilidad al poder tributario de establecer en el sistema tributario figuras o medidas que no se incorporan en el sistema para recaudar sino con finalidades diferentes, ya que, de acuerdo con el fundamento jurídico 5o. dela STG 221/1992, "es constitucionalmente posible que el legislador tributario, al regular cada figura impositiva, otorgue preeminencia a otros valores o principios, respetando, en todo caso, los límites establecidos por la Constitución...". ${ }^{19}$

Siguiendo con la idea anterior, en España existen diferencias en la contribución por rendimientos del trabajo y el recibido por los rendimientos de actividades empresariales de personas físicas bajo el régimen de estimación objetiva. En este caso, el legislador permite al contribuyente optar entre un sistema basado en la contabilidad mercantil o un sistema objetivo de estimación de la renta basado en signos, índices o módulos el cual dará como resultado una base imponible que puede no corresponderse con el rendimiento real de la actividad económica realizada según el artículo 31 de la Ley del Impuesto sobre la Renta de las Personas Físicas, (en adelante LIRPF). Por lo que bien puede coincidir, o puede superar el rendimiento real en perjuicio del contribuyente, o inclusive puede ser inferior en beneficio del contribuyente. En este último caso, incluso, se establece en el artículo 31.2.2 LIRPF una cláusula según la cual el exceso de renta obtenido sobre el rendimiento neto calculado a efectos fiscales queda libre de gravamen, sin que pueda ser conducido a la base imponible mediante su consideración como ganancia patrimonial. En consecuencia, el IRPF puede tener distinto resultado en dos supuestos de rendimientos del mismo volumen y con contribuyentes idénticos en circunstancias personales, pero con la diferencia de que uno obtenga rendimientos de actividades empresariales sometidas a régimen objetivo y otro, rendimientos del trabajo considerados siempre de forma íntegra. ${ }^{20}$

\section{Ibidem, p. 509.}

20 Los datos que aparecen en el diario económico Cinco Días, del 11 de noviembre de 2007, procedentes de la inspección de Hacienda en España ilustran y dan una visión más amplia desde un punto de vista fáctico de la desigualdad jurídica que se expone. Según el diario "...los inspectores de Hacienda denunciaron que la caída recaudatoria se concentra en las rentas empresariales y de capital. «En 2007, el 72\% de la recaudación del IRPF provenía de los rendimientos del trabajo, un nivel que con la crisis se ha elevado al 81'5 \%», explicó De la Torre. Ello, unido a la «espectacular caída de ingresos del impuesto de sociedades» demuestra que, pesa a los cinco millones de parados, son los asalariados 
En general, el sistema tributario está evolucionando hacia el incremento de la presión fiscal sobre los rendimientos del trabajo por su carácter de no deslocalizables y de factores como el consumo por medio de tributos indirectos que, como es sabido, plantean dificultades a la hora de adaptarse a principios como el de capacidad económica o a las circunstancias personales del contribuyente. Como en otras ocasiones, los motivos que permiten justificar estas tendencias son de carácter económico aunque, una vez más, podría contradecirse un principio de justicia en la distribución de los gastos públicos. ${ }^{21}$

\section{El Impuesto sobre la Renta de las Personas Físicas (IRPF) en España}

El Impuesto sobre la Renta de las Personas Físicas (en adelante, IRPF) es un tributo de carácter personal y directo que grava, según los principios de igualdad, generalidad y progresividad, la renta de las personas físicas de acuerdo con su naturaleza y sus circunstancias personales y familiares (artículo 1o., Ley IRPF).

Constituye el hecho imponible del IRPF la obtención de renta por el contribuyente cuyos componentes son los siguientes:

a) Los rendimientos del trabajo.

b) Los rendimientos del capital.

c) Los rendimientos de las actividades económicas.

d) Las ganancias y pérdidas patrimoniales.

e) Las imputaciones de renta establecidas por ley.

No obstante, a efectos de la determinación de la base imponible y del cálculo del IRPF, la renta se clasifica en general y del ahorro (artículo 6o., Ley IRPF).

El IRPF en España al igual que en México es una fuente muy importante de la recaudación para ese país. Como se podrá ver en los siguientes datos la recaudación de este impuesto es muy representativa, pues es la

quienes soportan una mayor carga fiscal", Cinco Días, "El riesgo de bajar impuestos en un contexto de crisis", disponible en: http://wrercincodias.com/artículo/economia/riesgo-bajarimpuestos-contexto-crisis, (fecha de consulta: 11 de noviembre de 2011, en Fernández Amor, op. cit.).

21 Ibidem, p. 522.

Esta obra está bajo una Licencia Creative Commons

Atribución-NoComercial-SinDerivar 4.0 Internacional, IIJ-UNAM.

Boletín Mexicano de Derecho Comparado, núm. 152, pp. 837-868. 
más importante tan sólo por debajo de las contribuciones de seguridad social.

\begin{tabular}{|l|c|}
\hline \multicolumn{1}{|c|}{ Contribuciones de España 2014 } & Porcentaje de la recaudación \\
\hline Contribuciones de seguridad social & $35 \%$ \\
\hline Impuesto sobre la Renta de Personas físicas & $23 \%$ \\
\hline Impuesto al Valor Añadido & $18 \%$ \\
\hline Impuestos Indirectos Bienes y Servicios & $10 \%$ \\
\hline Impuestos a la Propiedad & $7 \%$ \\
\hline Impuesto sobre Sociedades & $6 \%$ \\
\hline Otros impuestos & $1 \%$ \\
\hline & Total \\
\hline
\end{tabular}

FUENTE: OCDE.

A continuación, se ilustra la información de la tabla anterior de forma gráfica:

\section{RECAUDACIÓN EN ESPAÑA 2014}

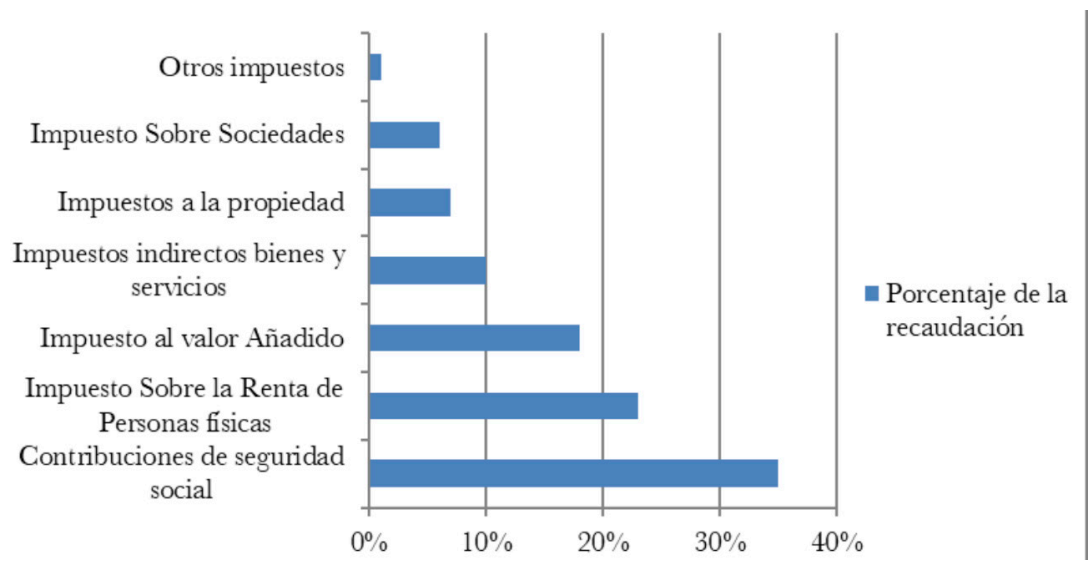

FUENTE: OCDE. 
A grandes rasgos, el cálculo del IRPF anual de una persona física con rendimientos del trabajo en España se determina como sigue, de acuerdo con los artículos 63 y 74 de la Ley IRPF:

1. Se suman los ingresos brutos percibidos en el año.

2. Se determinan las deducciones autorizadas que se restarán de los ingresos:

a) Deducciones por cuotas de seguridad social pagadas por el trabajador, principalmente y otros conceptos.

b) Gastos por rendimientos del trabajo que en la ley actual son por una cantidad fija de 2,000 euros (aproximadamente 41,460 pesos mexicanos).

c) Deducción adicional si el trabajador tiene alguna discapacidad.

3. Se determina el mínimo personal y el mínimo familiar (véase más adelante en este estudio en la sección 3.5 los importes).

4. Se calcula la exención por el mínimo personal aplicando la tarifa general y la autonómica (correspondiente a las comunidades autónomas o regiones que conforman España).

5. Se calcula el IRPF con la tarifa general y la autonómica.

6. Se resta al IRPF determinado en el punto anterior la exención determinada en el punto 4 y ese será el impuesto a pagar.

Esta determinación del IRPF por rendimientos del trabajo en España difiere a la de México en varios aspectos: primeramente, en España se tiene una cantidad fija mínima a deducir de forma personal; segundo, se pueden deducir las cuotas de seguridad social que paga el empleado; tercero, en España se toman en cuenta aspectos como el número de hijos del trabajador, si éste mantiene a sus ascendientes y si él o sus ascendientes y descendientes tienen alguna minusvalía.

Por todo lo anterior, es evidente que la tributación en la legislación española es más justa y apegada al principio de capacidad económica en comparación con el sistema de personas físicas en México. Asimismo, el IRPF en España permite la tributación individual o conjunta (artículo 82, Ley IRPF) es decir, una declaración conyugal que en ocasiones pue- 
de resultar incluso más benéfica que presentando dos declaraciones por separado.

\section{Cálculo del porcentaje de retención efectiva de un trabajador} de clase media en España

Según la $\mathrm{OCDE}^{22}$ en promedio de la tasa efectiva de ISR de una persona física en México en 2017 es de $9.47 \%$. El importe determinado por la OCDE es coincidente con el importe determinado en el cálculo 1 de la sección 1.3 en este estudio, toda vez que determinamos un importe muy similar: $9.49 \%$.

Por otro lado, en España, de conformidad también con el mismo estudio de OCDE, la tasa efectiva promedio de IRPF para un trabajador casado sin hijos en 2017 es de $11.30 \%$. Sin embrago, la tasa efectiva de un trabajador casado con dos hijos en España es de $9.94 \% .{ }^{23}$

Con base en las tasas anteriores podemos calcular la tasa efectiva de un trabajador de clase media en España de acuerdo a sus ingresos netos esperados de forma anual. Es decir, calcularemos la tasa después de deducir los gastos del hogar para el caso de un trabajador de clase media España tal como se hizo en el la sección 1.3 de este estudio con un trabajador de clase media de México, para el caso de España haremos dos supuestos para un trabajador casado sin hijos y para un trabajador casado con hijos.

22 OECD, Taxing wages 2017, disponible en; http://wwwoecd.org/tax/oecd-tax-ra teson-labour-income-continued-decreasing-slowly-in-2016.htm, (fecha de consulta: 14 de mayo de 2017).

23 Se consideró un trabajador casado porque la mayor parte de la población en edad productiva se encuentra casada de acuerdo con el INE en España, en este caso, para la tasa efectiva de la OCDE para nuestro estudio se consideró un trabajador con el 100\% del ingreso promedio y el cónyuge con solo un 33\% del ingreso promedio para no modificar el importe del ingreso de clase media del hogar. Para México no existe diferencia en la tributación del ISR por salarios de la persona física si fuera casado o tuviera hijos. 


\section{CÁlculo 3}

DETERMINACIÓN DE LA TASA EFECTIVA DE UN ASALARIADO

DE CLASE MEDIA EN ESPAÑA CASADO SIN HJJOS, CONSIDERANDO SUS GASTOS REALES

\begin{tabular}{lcc} 
& Euros & Pesos \\
Ingreso promedio anual & 27,447 & 569,882 \\
(x) Tasa efectiva según OCDE & $11.30 \%$ & $11.30 \%$ \\
\cline { 2 - 3 } (=) Total de IRPF & 3,102 & 64,397 a) \\
Ingreso promedio anual & 27,447 & 569,882 \\
(-) Gasto promedio en el hogar & 21,439 & 445,129 \\
\cline { 2 - 3 } (=) Ingresos netos & 6,008 & 124,753 b) \\
(-) IRPF Pagado & 3,102 & 64,397 a) \\
(=) Saldo para ahorro o inversión & 2,907 & 60,357 \\
$\quad$ & \\
$\quad$ Tasa efectiva sobre ingresos & & $51.62 \%$
\end{tabular}

FUENTE: Elaboración propia. ${ }^{24}$

Como se puede ver el resultado obtenido en el cálculo 3 anterior, no discrepa mucho de lo determinado para los trabajadores de clase de media de México, en el cálculo 2 de la sección 1.3 este estudio. Prácticamente también se le está reteniendo en impuestos la mitad del dinero que le queda al trabajador después de cubrir sus gastos en el hogar.

24 Tipo de cambio utilizado: 20.730, de acuerdo a la equivalencia del euro al último día de abril 2017 publicado en el Diario Oficial de la Federación el 8 de mayo de 2017.

Esta obra está bajo una Licencia Creative Commons

Atribución-NoComercial-SinDerivar 4.0 Internacional, IIJ-UNAM.

Boletín Mexicano de Derecho Comparado, núm. 152, pp. 837-868. 


\section{CÁlculo 4}

DETERMINACIÓN DE LA TASA EFEGTIVA DE UN ASALARIADO

DE GLASE MEDIA EN ESPAÑA GASADO Y CON 2 HIJOS, CONSIDERANDO SUS GASTOS REALES

\begin{tabular}{lcr} 
& Euros & Pesos \\
Ingreso promedio anual & 27,447 & 569,882 \\
(x) Tasa efectiva según OCDE & $9.94 \%$ & $9.94 \%$ \\
\cline { 2 - 3 } (=) Total de IRPF & 2,728 & 56,646 a) \\
Ingreso promedio anual & 27,447 & 569,882 \\
(-) Gasto promedio en el hogar & 21,439 & 445,129 \\
\cline { 2 - 3 } (=) Ingresos netos & 6,008 & 124,753 b) \\
(-) IRPF Pagado & 2,728 & $56,646 \quad$ a) \\
(=) Saldo para ahorro o inversión & 3,280 & 68,107 \\
$\quad$ Tasa efectiva sobre ingresos & & \\
$\quad$ netos (a /b) & $45.41 \%$ & $45.41 \%$
\end{tabular}

FUENTE: Elaboración propia ${ }^{25}$

A pesar de lo anterior, en el cálculo 4 notamos una disminución significativa de más de 6 puntos en la tasa efectiva de España que ocurre cuando el trabajador con el mismo ingreso tiene dos hijos, lo cual es una prueba de proporcionalidad en el impuesto y apego al principio de capacidad económica en el IRPF.

\section{Mínimo vital en la legislación española}

El mínimo vital, o mínimo exento personal y familiar como se le conoce en España, ha sido sujeto de amplios estudios doctrinales en ese país. ${ }^{26}$ En España, a diferencia de México sí existe un concepto de mínimo vital plenamente reconocido en su legislación fiscal.

El título V de la LIRPF es el destinado a valorar y cuantificar las circunstancias personales y familiares que son objeto de consideración en el impuesto.

\footnotetext{
25 Idem, nota 23.

26 Cfr. García Bueno, M., "El principio de capacidad...", cit., p. 61.
}

Esta obra está bajo una Licencia Creative Commons Atribución-NoComercial-SinDerivar 4.0 Internacional, IIJ-UNAM. Boletín Mexicano de Derecho Comparado, núm. 152, pp. 837-868. 
Por los montos que a continuación se mencionarán, las personas físicas no pagarán impuestos porque el legislador en España ha reconocido que estos montos deben estar exentos para que las personas físicas puedan tributar conforme a una capacidad contributiva real y que les permita tener una vida digna de acuerdo a sus circunstancias individuales.

El mínimo personal para todas las personas físicas es de 5,500 euros al año (aproximadamente 114,902 pesos mexicanos), estipulado en el artículo 57 de la LIRPF.

En cuanto al mínimo familiar se establecen los siguientes montos:

\section{Artículo 58 LIRPF:}

\begin{tabular}{|l|c|c|}
\hline Minimo familiar por descendientes & Euros & Pesos mexicanos \\
\hline Primer descendiente & 2,400 & 49,687 \\
\hline Segundo descendiente & 2,700 & 55,898 \\
\hline Tercer descendiente & 4,000 & 82,812 \\
\hline Cuarto y siguientes descendientes & 4,500 & 93,164 \\
\hline Incremento por cada hijo menor a 3 años & 2,800 & 57,968 \\
\hline
\end{tabular}

Artículo 59 LIRPF:

\begin{tabular}{|l|c|c|}
\hline Minimo familiar por descendientes & Euros & Pesos mexicanos \\
\hline Ascendientes $>65$ años pero $<75$ años & 1,150 & 23,808 \\
\hline Ascendientes $>75$ años & 2,550 & 52,793 \\
\hline
\end{tabular}

Artículo 60 LIRPF:

\begin{tabular}{|l|c|c|}
\hline Mínimo familiar por descendientes & Euros & Pesos mexicanos \\
\hline $\begin{array}{l}\text { Número de descendientes con grado de mi- } \\
\text { nusvalía }>=33 \% \text { y }<65 \%\end{array}$ & 3,000 & 62,109 \\
\hline $\begin{array}{l}\text { Número de descendientes con grado de mi- } \\
\text { nusvalía }>=65 \%\end{array}$ & 9,000 & 186,327 \\
\hline $\begin{array}{l}\text { Número de ascendientes con grado de mi- } \\
\text { nusvalía }>=33 \% \text { y }<65 \%\end{array}$ & 3,000 & 62,109 \\
\hline $\begin{array}{l}\text { Número de ascendientes con grado de mi- } \\
\text { nusvalía }>=65 \%\end{array}$ & 9,000 & 186,327 \\
\hline Trabajador con Minusvalía $>=33 \%$ y $<65 \%$ & 3,000 & 62,109 \\
\hline Trabajador con Minúsvalía $>65 \%$ & 9,000 & 186,327 \\
\hline
\end{tabular}

Esta obra está bajo una Licencia Creative Commons

Atribución-NoComercial-SinDerivar 4.0 Internacional, IIJ-UNAM.

Boletín Mexicano de Derecho Comparado, núm. 152, pp. 837-868. 
Tipo de cambio utilizado: 20.730, de acuerdo a la equivalencia del Euro al último día del mes de abril 2017 publicado en el Diario Oficial de la Federación el 8 de mayo de 2017.

Como fue señalado, la legislación española sí considera circunstancias subjetivas a la hora de calcular el IRPF y o se basa solo en aspectos cuantitativos de riqueza para determinar un impuesto como es el caso de la legislación mexicana.

\section{Algunos contrastes entre México y España}

México es un país con una clase media sumamente inferior en ingreso a España, adicionalmente existe mucha mayor desigualdad en la distribución del ingreso en México como se puede observar en la siguiente gráfica:

\section{PARTICIPACIÓN DEL 1\% DE MAYORES INGRESOS EN EL INGRESO TOTAL (AÑOS DIVERSOS, PARA MÉXICO} ESTIMACIONES PARA 2012)

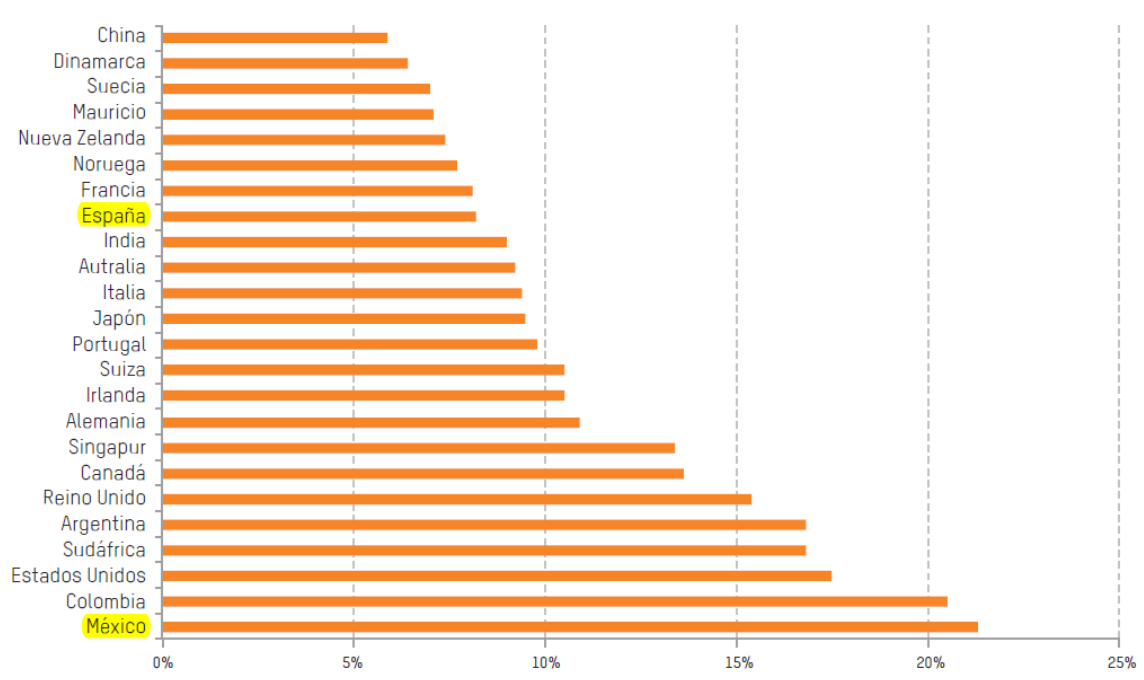

Fuente: Desigualdad extrema en México, concentración del poder económico y político. 
La gráfica anterior representa el porcentaje del ingreso total que le corresponde al 1\% de la población de mayores ingresos. Las cifras revelan que México es el país de la muestra en donde al 1\% más rico le corresponde un mayor porcentaje del ingreso total (21\%), siendo el país con mayor desigualdad de distribución de la riqueza. Por lo contrario, en España el porcentaje aproximado es del 8\% por lo que la desigualdad es notoriamente inferior. ${ }^{27}$

Desde luego que la desigualdad en la distribución de la riqueza se debe a múltiples factores económicos y sociales, pero consideramos que la política fiscal es un elemento clave para disminuir la desigualdad. Un Impuesto Progresivo sobre la Renta, como el IRPF que existe actualmente en España, tiene un importante efecto redistributivo, mayor incluso que muchas de las prestaciones públicas existentes. ${ }^{28}$

A diferencia de México el impuesto en España sí considera situaciones familiares y personales, debido a que existe un mínimo vital y familiar que repercute en la determinación del impuesto de las personas físicas. El tema del mínimo existencial ha sido de amplio estudio doctrinal de España. ${ }^{29}$

Otro aspecto que debemos hacer notar es que la calidad de los servicios públicos en España es muy superior a los que se reciben en México. En un estudio realizado por el Banco Mundial en el que se midieron diversos indicadores de prestación de servicios públicos, responsabilidad y buenas gestiones de gobiernos, se establecieron tres escalas: Buena gobernabilidad, mediana gobernabilidad y gobernabilidad pobre. ${ }^{30}$ Los aspectos evaluados se agruparon en las categorías de: participación ciudadana, orientación del gobierno, desarrollo social y gestión económica.

De las escalas anteriores, México se ubicó en mediana gobernabilidad, en tanto que España en la mejor escala de buena gobernabilidad, además se destaca que España obtuvo la puntuación más alta de todos los

27 Esquivel Hernández, G., Desigualdad extrema en México, concentración del poder económico y político, México, Oxfam México, 2015, p. 15.

28 Cantó Sánchez O., La capacidad redistributiva del sistema español de prestaciones e impuestos, España, Papeles de Economía Española, 2013.

29 Para mayor ampliación del tema se puede consultar a Herrera Molina, P., El mínimo personal y familiar en el impuesto sobre la renta de las personas fisicas, Madrid, Marcial Pons-IEF, 2000.

30 Véase Shah, Anwar, Prestación de servicios públicos, Bogotá, Banco Mundial-Mayol Ediciones, 2008.

Esta obra está bajo una Licencia Creative Commons

Atribución-NoComercial-SinDerivar 4.0 Internacional, IIJ-UNAM.

Boletín Mexicano de Derecho Comparado, núm. 152, pp. 837-868. 
países evaluados en la categoría de desarrollo social, en conjunto con los países de Canadá, los Países Bajos y el Reino Unido.

En una entrevista realizada el 23 de mayo de 2017 en la Ciudad de México al doctor Pedro Carrasco, director de la Facultad de Ciencias Jurídicas y Sociales en la Universidad de Castilla la Mancha de Toledo, España, declaró que los servicios públicos en España, particularmente los de medicina, son de una excelente calidad en España. También expresó que en México todavía falta un gran camino por recorrer en el tema de los servicios públicos para que la población sienta que los impuestos que está contribuyendo son bien retribuidos.

\section{CONCLUSIONES Y RECOMENDACIONES FINALES}

Es evidente y lamentable que el Estado mexicano le está "cargando la mano" a los asalariados, como se señaló en la introducción de este estudio, este régimen ha contribuido más en términos absolutos a la carga fiscal del país incluso que las personas morales, tal como ocurrió en el 2014. En el caso de España pudimos ver que esto es coincidente pues el IRPF de los rendimientos del trabajo también contribuye en mayor medida que el impuesto de sociedades en España.

A pesar de lo anterior, consideramos que el IRPF es un impuesto que es más redistributivo que el ISR de las personas físicas en México porque la concentración de los ingresos en España es notoriamente menor y tienen una mayor clase media. Asimismo, la clase media trabajadora de España se encuentra muy cercana al promedio de los países de la OCDE por nivel de ingresos, en tanto que los trabajadores de México son los que tienen menores niveles de ingresos de la OCDE.

Consideramos que la definición de una persona de clase media en México para el Inegi difiere de lo que nosotros consideraríamos un nivel económico suficiente, pues para este organismo una persona de clase media es la que tiene un ingreso no mayor de 10,500 pesos mexicanos al mes. Este pensamiento institucional es prueba inequívoca de una mentalidad mediocre y aceptación de rezago en el que vivimos. Esa definición de clase media es análoga a la exigua cantidad de salario mínimo de 80.04 pesos diarios con los cuales nuestras instituciones han alegado que se puede subsistir. 
Luego de todas las premisas y análisis en este estudio podemos concluir que la legislación actual en el régimen de salarios en México no es un impuesto que respete la capacidad contributiva de las personas físicas, particularmente de aquellas personas de clase media a las que ya no se les concede subsidio al empleo y tienen que contribuir con un alto porcentaje de sus ingresos netos, puesto que el régimen concede limitadísimas deducciones personales y no existe un reconocimiento del mínimo personal y familiar al contribuyente.

Planteamos el siguiente ejemplo a manera de ilustrar lo anterior. En México, un asalariado que gana al mes 15,000 pesos y es soltero y solamente incurre en gastos propios, va pagar el mismo ISR que un asalariado que gane los mismos 15,000 pesos mensuales pero que tenga que mantener a dos hijos y mantener a sus padres ancianos. Es evidente que estas personas tienen una situación familiar completamente diferente, y el Estado mexicano está violando el principio de capacidad contributiva al no reconocer la situación personal de los mexicanos al momento de tributar.

La situación anterior no ocurriría en España, debido a que el IRPF sí considera diversos aspectos para la tributación en función de la situación personal y familiar que disminuyen la base de la contribución como se ha mencionado en este estudio.

A pesar de que el pleno de la SCJN en México rechazó los amparos basados en el concepto del derecho al mínimo vital, consideramos que es necesario volver a analizar este principio para incorporarlo a nuestra legislación, en especial a la luz de la nueva Ley del Impuesto sobre la Renta promulgada en 2014 que establece aún mayores limitantes a las deducciones personales y se está afectando severamente al régimen de salarios el cual únicamente puede aplicar dichas deducciones personales para disminuir su contribución.

Coincidimos plenamente con García Bueno cuando afirma que es patético pensar que un salario mínimo, (sobretodo el establecido en México, de 80.04 pesos por día), puede ser identificado como un mínimo existencial. El régimen de personas físicas, particularmente el de salarios, es completamente injusto: no valora la aptitud para pagar el impuesto del contribuyente, la base gravable se constituye con el ingreso bruto, se minora la cuota con un subsidio al empleo que sólo atiende a importes

Esta obra está bajo una Licencia Creative Commons

Atribución-NoComercial-SinDerivar 4.0 Internacional, IIJ-UNAM.

Boletín Mexicano de Derecho Comparado, núm. 152, pp. 837-868. 
cuantitativos de riqueza y nunca se valora la situación personal y familiar del contribuyente. ${ }^{31}$

En suma, consideramos que con el régimen actual en México los asalariados de clase media están contribuyendo de forma excesiva, ya que no se les aplica un subsidio al empleo, sus deducciones personales son muy limitadas y no existen en la legislación mexicana conceptos de deducción que atiendan a las circunstancias personales para determinar un mínimo vital.

Asimismo, la calidad de los servicios públicos que recibimos en el país discrepa mucho de los recibidos en países de primer mundo como en España, lo cual obliga aún más a las personas de clase media a incurrir en gastos porque el Estado no satisface todas las necesidades de la población de forma óptima. Gastos que, además, insistimos, no se pueden deducir totalmente y a los cuales se les exigen muchísimos requisitos formales para poder deducirlos.

Recomendamos de forma urgente evaluar las deducciones personales aplicables en la LISR actual de México, pues como se demostró con los ejemplos numéricos la carga impositiva para los asalariados es elevada porque no pueden aplicar una cantidad sustancial de elementos neutralizadores (deducciones) de su base gravable y se está pagando sobre una renta bruta.

Puede ser materia de un futuro estudio, analizar qué gastos adicionales deberían ser deducibles en la legislación mexicana, necesarios para garantizar un verdadero mínimo existencial para las personas físicas, que contribuyan a incrementar y fortalecer a la clase media. A priori, pensamos que los siguientes conceptos deberían de evaluarse:

- Gastos de arrendamiento de vivienda.

- Un porcentaje de gastos de alimentos.

- Un porcentaje de gastos de vestido.

- Un importe de gastos de medicinas al año que puede incrementar en función de ciertos padecimientos.

- Gastos de transporte público.

31 García Bueno, M., "El Impuesto sobre la Renta de las personas físicas a la luz de los principios de igualdad y capacidad contributiva”, en Ríos Granados, Gabriela (coord.), Temas selectos de derecho tributario, México, Porrúa-UNAM, 2008, p. 96. 
- Deberían ser totalmente deducibles los gastos en colegiaturas y gastos médicos, sobretodo porque el Estado mexicano no provee actualmente de suficientes hospitales y escuelas públicas de calidad para la población, los cuales son dos servicios elementales para el desarrollo personal y del país a largo plazo.

Todos los gastos anteriores debieran atenderse en función de la situación familiar del contribuyente para lograr una contribución justa y apegada a la capacidad contributiva.

Nuevamente, coincidimos con García Bueno cuando menciona que se debe buscar la capacidad contributiva de las personas atendiendo a la progenie y la condición familiar de una persona, donde se atienda al número de hijos, gastos de manutención, vivienda, salud y disponibilidades económicas son de gran alcance para conocer su aptitud tributaria. En nuestra Constitución no existe referencia al tratamiento fiscal de la familia, quedando desprotegida en uno de sus flancos más débiles: el económico. El principio de justicia, entendido, en una de sus partes, como capacidad contributiva rige en México para el individuo en particular, pero sin tener en cuenta la base familiar, lo cual es un grave fallo. ${ }^{32}$

De igual forma, consideramos que puede ser objeto de otro estudio el impacto en la recaudación que tendría la mayor deducción de gastos de los asalariados. En México existe mucha evasión en ciertos sectores, como por ejemplo el del arrendamiento de inmuebles, ${ }^{33}$ una estrategia bien implementada por el legislador que permitiera a los contribuyentes por salarios deducir el alquiler de vivienda implicaría que éstos van a solicitar el comprobante fiscal por su pago y por lo tanto se disminuiría la evasión en el arrendamiento de inmuebles. De igual forma puede ocurrir con otros conceptos como la alimentación, vestido, transporte, por mencionar algunos. Por lo tanto, no significa que el fisco vaya a dejar de percibir ingresos en el ISR por salarios, sino que se distribuiría más equitativamente la carga fiscal.

32 García Bueno, M., El principio de capacidad contributiva a la luz de las principales aportaciones doctrinales en Italia, España y México, México, Tribunal Federal de Justicia Fiscal y Administrativa, 2002, p. 237.

33 En un artículo publicado por el Economista el 8 de abril de 2013 se menciona que la evasión por alquiler de inmuebles, es del $64 \%$ de acuerdo con un estudio según el Centro de Estudios de las Finanzas Públicas de la Cámara de Diputados. 
México debe tomar el ejemplo de sociedades más avanzadas en términos tributarios como el de España. Si bien todo sistema es perfectible y España tiene sus propios problemas, como por ejemplo, también los que están contribuyendo en mayor proporción son los asalariados, queda claro que en México se requiere de forma urgente una reforma para un sistema tributario más justo para las personas físicas, en particular, de los rendimientos del trabajo que es un factor que se debería de proteger más por la importancia social que tiene en la estabilidad del país.

Se necesita una legislación que respete la capacidad contributiva real de las personas físicas de acuerdo a su situación personal y familiar, y sobretodo que el sistema tributario proteja el factor trabajo que se encuentra en una situación precaria en cuanto a los ingresos que obtiene y la carga fiscal que solventa. Sabemos que México tiene el ingreso más bajo en salarios de todos los países de la OCDE, y a pesar de esto, los asalariados siguen siendo los que más contribuyen a la recaudación del país, esto es por demás injusto e inequitativo.

La legislación tributaria mexicana necesita impulsar a un activo tan valioso como son sus trabajadores. Se necesita acrecentar la clase media y consolidarla con un poder económico fuerte y estable, es la única manera de reducir la injusticia y brecha excesiva entre ricos y pobres que existe en México. La experiencia de otros países nos debe abrir los ojos, a mayor clase media y con mejor nivel económico, mayor estabilidad social y progreso económico.

\section{BIBLIOGRAFÍA}

BÁrcena, Alicia y SERRA, Narcís, Clases medias y desarrollo en América Latina, Chile, CEPAL-CIDOB, 2010.

Cantó SÁnchez, Olga, La capacidad redistributiva del sistema español de prestaciones e impuestos, España, Papeles de Economía Española, 2013.

ESQUivel HeRnÁNDEZ, Gerardo, Desigualdad extrema en México, concentración del poder económico y político, México, Oxfam México, 2015.

Fernández Amor, José Antonio y Masbernat, Patricio, "La vigencia de los principios de justicia tributaria en España: aportaciones para un debate", Estudios Constitucionales, Chile, vol. 11, núm. 2, 2013. 
Flores Zavala, Ernesto, La justicia en los impuestos, México, Librería Madero, 1955.

García Bueno, Marco César, El principio de capacidad contributiva a la luz de las principales aportaciones doctrinales en Italia, España y México, México, Tribunal Federal de Justicia Fiscal y Administrativa, 2002.

García Bueno, Marco César, "El principio de capacidad contributiva como criterio esencial para una reforma fiscal", en Ríos Granados, Gabriela (coord.), Conceptos de reforma fiscal, México, UNAM, 2002.

González García, Eusebio, Concepto y contenido del derecho tributario, México, Porrúa, 2005.

Herrera Molina, Pedro, Capacidad económica y sistema fiscal, análisis del ordenamiento español a la luz del derecho alemán, Madrid, Marcial Pons, 1998.

Herrera Molina, Pedro, El mínimo personal y familiar en el impuesto sobre la renta de las personas fisicas, Madrid, Marcial Pons-IEF, 2000.

Instituto NaGional De EstadístiGa Y GeOgRAFÍA, Encuesta Nacional de Ingresos y Gastos en los Hogares, 2014, disponible en: http://wrerw.beta.inegi. org. $m x /$ app/biblioteca/ficha.html?upc $=702825072728$.

OEGD, Data Spain, disponible en: https://data.oecd.org/spain.htm.

OECD, Taxing wages 2017, disponible en: http://wrere.oecd.org/tax/oecd-taxrates-on-labour-income-continued-decreasing-slowly-in-2016.htm.

OECD, Revenue Statistics México, disponible en: https://wrereoecd.org/tax/ revenue-statistics-mexico.pdf.

POnt Mestres, Magín, La justicia tributaria y su formación constitucional, Barcelona, Estudios sobre temas tributarios actuales, 1985.

Rosembuj Erujimovich, Tulio Rául, Elementos de derecho tributario, Barcelona, PPU, 1998.

SERVICIO DE ADMINISTRACIÓn TRIBUTARIA, Reporte anual 2015 y retos 2016, disponible en: http://wrere.sat.gob. $m x /$ transparencia/transparencia_focalizada/Documents/itg2015_t4/ReporteAnual2015_Retos2016.pdf.

SHAH, Anwar, Prestación de servicios públicos, Bogotá, Banco Mundial-Mayol Ediciones, 2008.

Venegas Álvarez, Sonia, Derecho fiscal parte general e impuestos federales, México, Oxford, 2016.

Esta obra está bajo una Licencia Creative Commons

Atribución-NoComercial-SinDerivar 4.0 Internacional, IIJ-UNAM.

Boletín Mexicano de Derecho Comparado, núm. 152, pp. 837-868. 